\title{
Load Frequency Control of Multi - area Hybrid Power System by Artificial Intelligence Techniques
}

\author{
Kassim A. Al-Anbarri \\ Electrical Engineering Dep., \\ Faculty of Enginnering, \\ Almustansiriyah University \\ Baghdad,Iraq
}

\author{
Abbas H. Miri \\ Electrical Engineering Dep., \\ Faculty of Enginnering, \\ Almustansiriyah University \\ Baghdad,Iraq
}

\author{
Sarah Abbas Hussain \\ Electrical Engineering Dep., \\ Faculty of Enginnering, \\ Almustansiriyah University \\ Baghdad,Iraq
}

\begin{abstract}
This paper presents the application of different Artificial intelligence techniques on the tuning of PID controller in a load frequency control system. The algorithms of PSO technique, Genetic algorithm technique, and Artificial Bee Colony technique has been applied on four area power system with six tie lines. The system dynamic model is formulated in state variables form. A comparison between these techniques with different performance indices is presented. The effect of including different types of generating units (i.e. a hybrid power system) on the dynamical performance of a load frequency control is also presented. Three types of control criterion are adopted. Simulation of the applied artificial techniques on a typical hybrid power system has been carried out. It is observed that a hybrid power system can track the load fluctuation quickly.
\end{abstract}

\section{Keywords}

Load frequency control, Genetic algorithm, Artificial Bee Colony, Hybrid power system.

\section{INTRODUCTION}

The Load Frequency Control (LFC) or Automatic Generation Control (AGC) plays a vital role in electrical power system. It ensures a sufficient, good quality and reliable power supply.

A good quality power system is the one which characterized by a constant voltage, constant frequency and a pure sinusoidal waveform. It is well known in power system dynamic that the rate of electric energy production at each moment must equal the rate of electric energy consumed and energy losses. Any power imbalance between the power generated and the power consumed will change the stored kinetic energy in the rotating masses of the system. Since the stored kinetic energy depends on the speed of the rotating masses (rotors of the turbines and generators). This imbalance in power will be sensed as a speed (frequency) deviation in the generators.

The consumed power in the system undergoes changes throughout the day. It is important to chase these changes by corresponding change in the generated power by a LFC system. The main objective of a LFC is to maintain zero frequency deviation in the system following a step change in the load. This is obtained by regulating the generated active power to match consumer active power and system power losses. This can be achieved by two control loops. A primary (coarse) control loop through a governor and a secondary (fine) control loop. The secondary loop guaranties that frequency deviation will vanish In an interconnected power system another important aim of LFC should be considered .This second main aim is to maintain zero tie line power deviation following a step load change.
The load frequency control was approached by classical design methods during the early years of research. These methods based on integral control [1]. Unfortunately, these tools are unable to deal successfully with all dynamic features in the system as the growth of power demand in the world tends to increase. The increased number of power areas and tie lines impose difficulties in determining the optimum values of parameters of the LFC controller. The modern control methods is become an efficient alternative. Artificial intelligence techniques are found to be promising tool to optimally minimize the transient dynamics and control efforts in a load frequency control. Many articles have been published which focus on the application of AI technique in LFC controller. But most of them either implemented for two area power system or systems with only steam and hydro turbines. An algorithm for a LFC of thermal system interconnected with thermal system has been studied in [2] by using a PID controller tuned through a simple genetic algorithm (GA).

Soundarrajan et al. [3] proposed fuzzy logic LF controller. An attempted to use the neural network LF controller for two area power system was presented in [4]. Surya Prakash et al [5] proposed a control method developed by using Artificial Neural Network (ANN).

The control algorithm shows that the steady state error of frequencies and tie-lines power are maintained in a given tolerance limitations. An $\mathrm{ABC}$ algorithm to tune the parameters of PI and PID load frequency controllers of the interconnected reheat thermal power system has been developed by Haluk Gozde et al. [6]. In paper [7], the researcher proposed a PID load frequency controller based on Imperialist Competitive Algorithm ICA. The load frequency control has been approached in[8] by using Proportional Integral (PI) controller based on Craziness Particle Swarm Optimization (CPSO). Mohammad Amin Hedari et al [9] proposed fuzzy logic load frequency controller interconnected power system.

Many utilities in the developing countries have introduced gas units and diesel units as a form of energy conversion. The dynamic characteristics of steam and hydro units are different from that of gas and diesel units.

For example, a new gas and diesel units had committed into Iraqi system. The gas units production contributes $61 \%$ of the total production. The diesel unit's production contributes $2 \%$ of the total production [10]. It is important to study the interaction of the dynamics of these units in a LFC system. A hybrid power system may be described dynamically by a high order of system of differential equation. The paper addressed the following aspects: 
1. Tuning the PID controller parameters by using and different Artificial Algorithms (AI) with different Performance Indices (PI).

2. Make a comparison between these AI algorithms in terms of dynamic performance of the controllers.

3. The effect of the dynamic characteristics of the diesel units on the overall performance of a load frequency control.

This paper is organized as follows: Section 2 introduce the dynamic model of the basic elements of a load frequency control system and the state space formulations. The application of $\mathrm{ABC}$ on tuning $\mathrm{LF}$ controller is presented in Section 3. Section 4 contains the results obtained and discussion. The conclusion is given in Section 5.

\section{SYSTEM DYNAMIC MODEL}

The basic elements of a LFC system may be represented by the following mathematical models. The modeling of speed governing system depends on the type of power station which can be classified as follows [11]:
1. Steam turbine unit
2. Hydro turbine unit.
3. Gas turbine unit.
4. Diesel unit.

\subsection{Speed governing system of steam unit}

Speed governor system for steam turbine can be represented by the block diagram given in Figure (1).

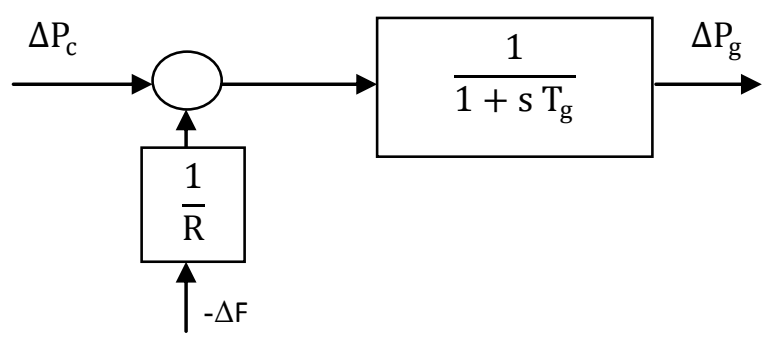

Figure 1: Model of speed-governing system of steam turbine

Where:

$\mathbf{T}_{\mathbf{g}}$ : The governor response time in second

$\mathbf{R}$ :governor speed regulation in

$\Delta \mathbf{P}_{\mathbf{c}}$ : The command signal

$\Delta \mathbf{f}=$ frequency deviation in $\mathrm{Hz}$

$\Delta \mathbf{P g}$ : The governer control signal

\section{2 .Speed governing system for hydro-turbines :}

Speed governor system for hydro turbine can be represented by the block diagram given in Figure (1).

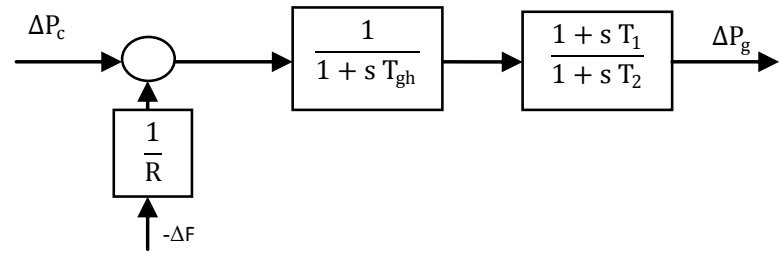

Figure 2: Model of speed-governing system of hydro turbine

Where :

$\mathrm{T}_{1}$ : Speed governor reset time in seconds.

$\mathrm{T}_{2}$ : Transient droop time constant in seconds.

$\mathrm{T}_{\mathrm{gh}}$ : Hydraulic governor response time in seconds.

3.Speed Governor System for Gas Turbine :

Speed governor system for gas turbine can be represented by the block diagram given in Figure (3).

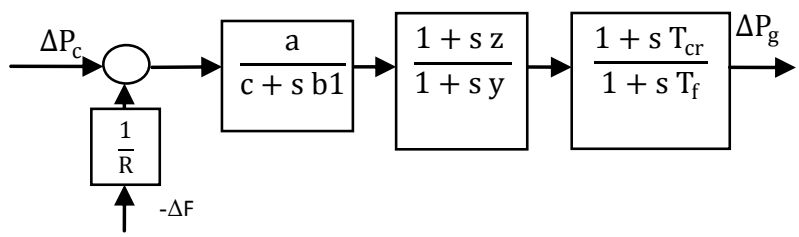

Figure 3: Model of speed-governing system of gas turbine Where

$\mathrm{z}$ and $\mathrm{y}$ : lead and lag time constants of speed governor in sec

a, b1 and c: Valve positioned constants

$\mathrm{T}_{\mathrm{f}}$ : Fuel time constant

$\mathrm{T}_{\mathrm{cr}}$ : Combustion reaction time delay

\section{Speed Governor System for diesel unit :}

Speed governor system for diesel unit can be represented by the block diagram given in Figure(4).

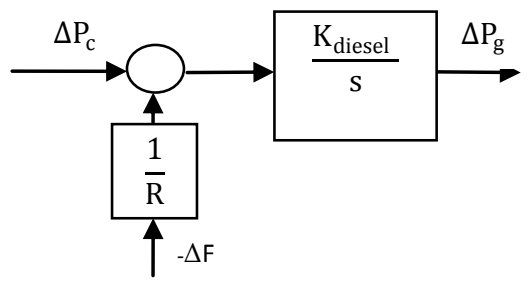

Figure 4: Model of speed-governing system of diesel turbine

Where :

$\mathrm{K}_{\text {diesel }}$ : diesel gain constant

5.Steam Turbine System:reheat 


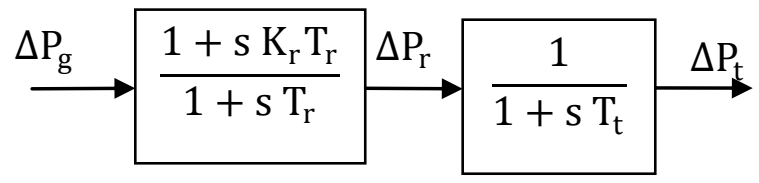

Figure(5): The block diagram for reheat steam turbine Where :

$\mathrm{K}_{\mathrm{r}}$ : re-heat steam turbine Coefficient

$\mathrm{T}_{\mathrm{r}}:$ Re-heater time constant

$\mathrm{T}_{\mathrm{t}}$ : Turbine time constant

\section{Hydro-Turbine System:}

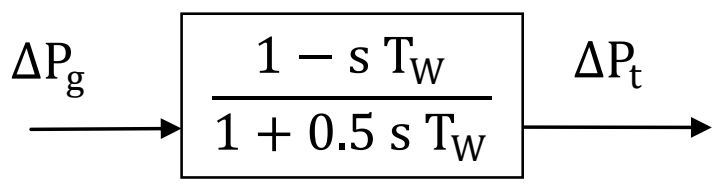

Figure(6): The block diagram for hydro turbine Where :

$\mathrm{T}_{\mathrm{W}}:$ water time constant

3.Gas turbine system

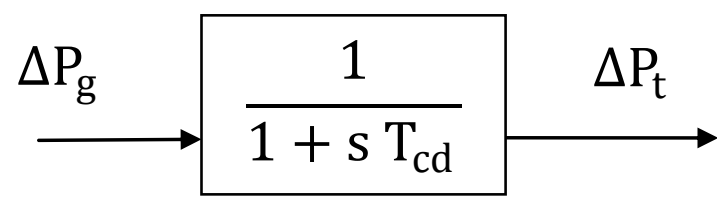

Figure(7): The block diagram for gas turbine

Where : $\mathrm{T}_{\mathrm{cd}}$ is compressor discharge time constant 4.Diesel engine system

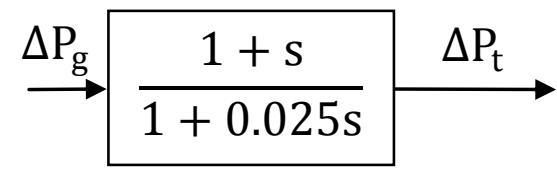

Figure(8): The block diagram for diesel unit

2.5.3

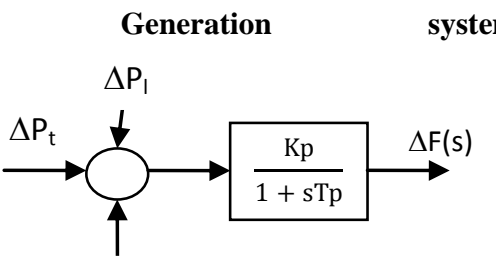

$\Delta \mathrm{P}_{\text {tie }}$

Figure(9): Block diagram of the generation area

Where:
$\Delta \mathrm{P}_{1}=$ deviation in the electrical load

$\Delta \mathbf{P}_{\text {tie }}=$ deviation in tie line power interchange

$\mathrm{K}_{\mathrm{p}}=$ power system gain constant, Hz/puMW

$\mathrm{T}_{\mathrm{p}}=$ power system time constant, sec

$\left.\left.\Delta \mathbf{f}=\frac{\mathrm{K}_{\mathrm{p}}}{1+\mathrm{s} \mathrm{T}_{\mathrm{p}}}\right)-\Delta \mathrm{P}_{\mathrm{l}}(\mathrm{s})-\Delta \mathrm{P}_{\text {tie }}(\mathrm{s})\right)$
2.5.4 $\mathrm{T}$

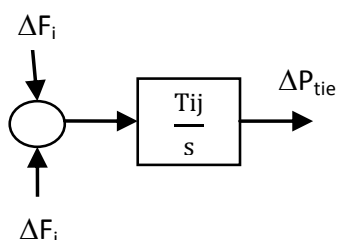

$\Delta \mathrm{F}_{\mathrm{j}}$

Figure (10): Linear representation of tie-line

\section{ABC ALGORITHM}

The Artificial Bee Colony (ABC) is a swarm algorithm that was introduced by Karaboga in 2005[12], to optimize numerical problems. The intelligent foraging behavior of honey bees inspired the $\mathrm{ABC}$.

The model consists of three important components: employed and unemployed foraging bees, and food source.

There are two types of unemployed foragers: Scouts and Onlookers.

Two leading modes of behavior which are necessary for selforganizing and collective intelligence are defined by the model [12]:

1. Recruitment of foragers to rich food sources resulting in positive feedback.

2. Abandonment of poor sources by foragers causing negative feedback.

Bee dances are the way that the onlooker bees know the location, direction, the food amount and food quality .There are two types of bee dancing [12] :

\section{1. circle dance}

In circle dance figure (11) the employed bee start running circularly with making stops to give samples of the honey to the bees following the dance. The onlooker bees take the information from the employed bee directly by touching the dancer feet. This dancing used for short distant and the food source near the hive without knowing the direction of the food source.

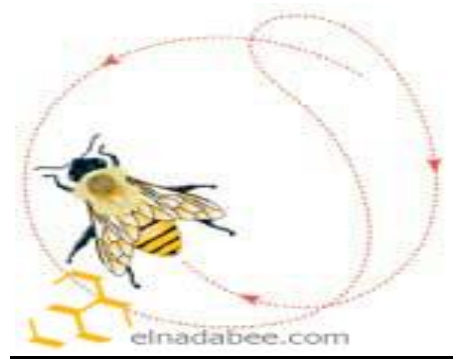

Figure (11): circle dance 


\section{Waggle tail dance ( like number 8 ) :}

This dance in figure (12) gives the onlooker bees information about the distant and direction of the food source .It starts running circularly in one direction then running circularly in the other direction with waggle the tail. The sharing information time means the distance, for example $(1 \mathrm{sec}=1 \mathrm{Km})$. These dances achieved on a disc called the dancing area. The bees use the sun to determine the food angle directions without seeing the sun to determine the direction of the food. If the bee dances in 20 degree on the disc right to the vertical line with the sun means the flying is also in 20 degree right to the sun and so on. And when the sun moves, the bees return to the hive to inform about the change in the coordinates. There is proportional relation between the distance of the food and the hive. Whenever the dance was faster that means the food source is closer to the nest and vice versa.

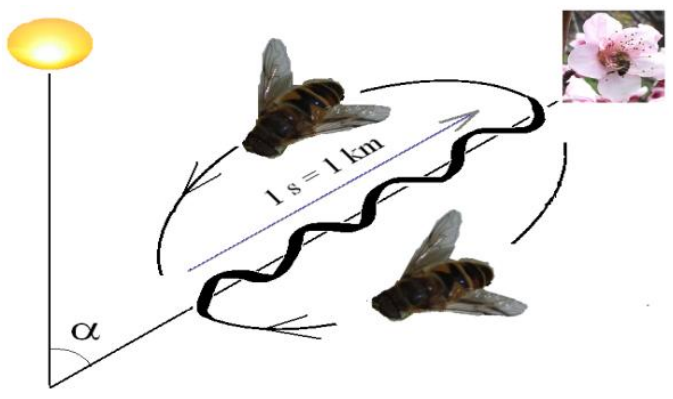

Figure(12):waggle dance

\subsection{Mathematical Model of ABC [26]}

Detailed of the ABC Algorithm are as follows:-

1: Initialize the population $\mathrm{xi}, \mathrm{j}$ of solutions.

2: Compute the population.

3: Cycle $=1$.

4: Generate new solutions (food source positions) $V_{i, j}$ next to $\mathrm{X}_{\mathrm{i}, \mathrm{j}}$ for the employed bees using the equation: $\mathrm{V}_{\mathrm{i}, \mathrm{j}}=\mathrm{X}_{\mathrm{i}, \mathrm{j}}+\Phi_{\mathrm{i}, \mathrm{j}}$ $\left(\mathrm{X}_{\mathrm{k}, \mathrm{j}}-\mathrm{X}_{\mathrm{i}, \mathrm{j}}\right) \ldots(3.1)$

In defining the performance index, the constraints and specifications for load frequency control should be taken into considerations. The constraints that should be considered are:

1. The frequency and the tie line power exchange should be returned to their nominal and prescheduled values after a step change in the load.

2. Assure the stability of the entire control loop.

The performance indices PI adopted in the present paper are:

1. Integral of Absolute magnitude of Error (IAE) given by the following formula

$I A E=\int_{0}^{T}|e(t)| d t$

2.Integral of Square of Error (ISE)given by the following formula

$I S E=$

$$
\mathrm{ISE}=\int_{0}^{T} e^{2}(t) d t
$$

3.Integraı oı 1 1me muıpilea dy Aosolute Error (ITAE)
( $\mathrm{k}$ is a solution in the neighborhood of $\mathrm{i}, \Phi$ is a random number in the range $[-1,1]$

5: Insert the greedy selection process between $x i$ and $v i$

6: Evaluate the probability values $\mathrm{Pi}$ for the solutions xi depending on the fitness values using:- $P_{i}=\frac{\text { fit }_{i}}{\sum_{\mathrm{i}=1}^{\mathrm{SN}} \mathrm{fit}_{\mathrm{i}}}$

The fitness values fit calculated as the following:- fit $_{\mathrm{i}}=$ $\begin{cases}\frac{1}{1+\mathrm{f}_{\mathrm{i}}} & \text { if } \mathrm{f}_{\mathrm{i}} \geq 0 \\ 1+a b s\left(f_{i}\right) & \text { if } f_{i}<0\end{cases}$

Pi value between $[0,1]$.

7: Find the new solutions for the onlookers (new positions) $\mathrm{V}_{\mathrm{i}}$ from the solutions $\mathrm{X}_{\mathrm{i}}$. The selection depends on $\mathrm{Pi}$, and calculates them.

\section{RESULTS AND DISCUSSION}

The proposed algorithms are applied to two types of power systems. The first system is a non-hybrid one which consists of four areas system consists of thermal and hydro units only. The second system is a four areas hybrid system consists of thermal, hydro, gas, and diesel units like figure 13. The parameters of the first four areas system are given in Appendix A1. While the parameters of the second four areas system are given in Appendix A2. The mathematical model of the system is simulated using MATLAB environment. The load disturbance is assumed to be a step change in the load of area 1 with $1 \%$ and $10 \%$.Several objective functions (performance indices) are considered which are based on integration of the error. The performance indices being used are the Integral of Absolute Error (IAE), Integra of Squared Error (ISE), Integral of Time multiply by Absolute Error (ITAE), and Integral of Time multiplied by squared error( ITSE).In the present work, the four areas are assumed to have a PID controller with three gain parameters. The parameters of the PID controller are $K_{p}, K_{i}$ and $K_{d}$ which are the proportional, integral and derivative gains respectively. The input to each controller is area control error given by the following equation:

$e=\sum \Delta P_{t i e}+B \sum \Delta F$

4.Integral of Time multiplied by Square Error (ITSE)

$$
\mathrm{ITSE}=\int_{0}^{T} t e^{2}(t) d t
$$

The function $e(t)$ is summation of the frequency error in each area and Tie line power deviation for each tie line. While $T$ represent the time range of simulation.

The system outputs are (Four Frequency deviations and six tie line deviations) namely ( $\Delta \mathbf{F}_{\mathbf{1}}, \Delta \mathbf{F}_{\mathbf{2}}, \Delta \mathbf{F}_{3}, \Delta \mathbf{F}_{4}, \Delta \mathbf{P}_{\text {tie, 12 }}, \Delta \mathbf{P}_{\text {tie, 13, }}$, $\Delta \mathbf{P}_{\text {tie,14, }} \Delta \mathbf{P}_{\text {tie,23, }}, \Delta \mathbf{P}_{\text {tie,24 }}$ and $\Delta \mathbf{P}_{\text {tie,34) }}$.

For $1 \%$ step load change in area 1, the tuned PID controller gains for different performance indices and different AIs(i.e.GA, PSO and ABC) are given in the tables (4.1 to 4.4) for non-hybrid system and[4.13 to 4.16] for hybrid system.

The dynamic response of the systems for a step change of $1 \%$ in the load of area 1 are given in Figures [14 to 21] for nonhybrid system and [22 to 29] for hybrid system. These figures are for different AI techniques and different PI. These Figures reveal that the PID controller can force the deviation in the frequency and tie line power deviation to zero. It is also

$$
\mathrm{ITAE}=\int_{0}^{T} t|e(t)| d t
$$


observed for the most cases that the tuned parameters of PID controllers using $\mathrm{ABC}$ technique are very effective in reducing the settling time and damping the maximum overshoot. The results regarding these dynamic characteristics are presented in tables [4.5 to 4.12] for non-hybrid system and [4.17 to 4.24] for hybrid system. It can be observed that using the criterion of Integral of Absolute Error (IAE) give better results

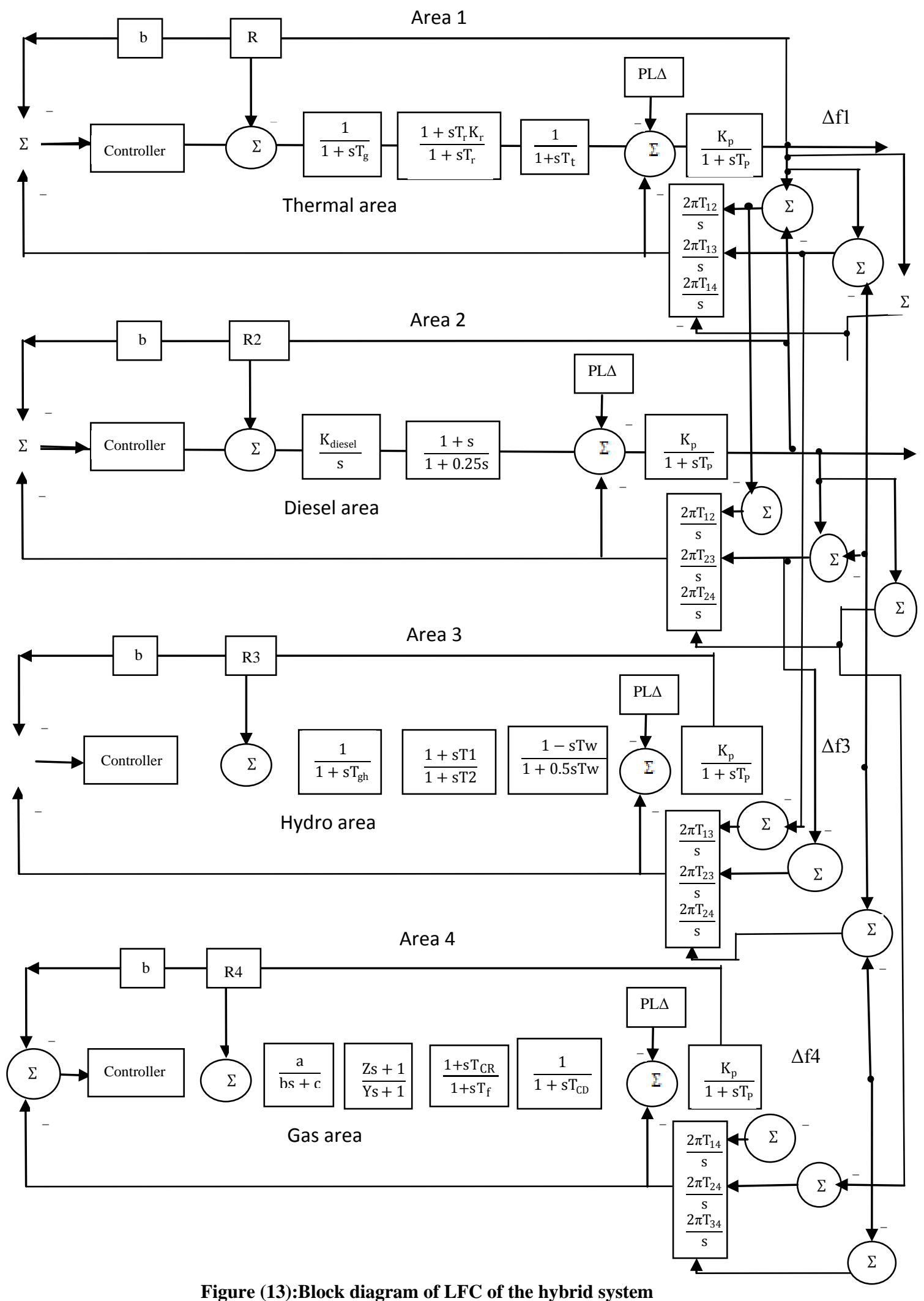

Figure (13):Block diagram of LFC of the hybrid system

LFC Using Four Areas Power System With non-hybrid Units: 
1. For $1 \%$ load change in area 1 :

$1 \%$ IAE

Table (4.1):PID tuned controller gains using IAE ISE

\begin{tabular}{|c|c|c|c|}
\hline PID & GA & PSO & ABC \\
\hline Kp1 & 1.143 & -0.093 & 10 \\
\hline Ki1 & 0.529 & 0.595 & 10 \\
\hline Kd1 & 0.875 & -0.024 & 3.55 \\
\hline Kp2 & -0.5 & -0.093 & -0.33 \\
\hline Ki2 & -0.093 & -0.032 & 0.459 \\
\hline Kd2 & $-\mathbf{0 . 3 6}$ & -0.277 & -0.381 \\
\hline Kp3 & 0.127 & -0.164 & 0.713 \\
\hline Ki3 & 0.053 & -0.101 & 10 \\
\hline Kd3 & -0.434 & -0.019 & -0.046 \\
\hline Kp4 & $\mathbf{1 . 2 8 5}$ & -0.143 & -2.007 \\
\hline Ki4 & -0.001 & 0.057 & 0.555 \\
\hline Kd4 & -0.706 & -0.209 & -2.73 \\
\hline
\end{tabular}

Table (4.2):PID tuned controller gains using ISE

ITAE

\begin{tabular}{|c|c|c|c|}
\hline PID & GA & PSO & ABC \\
\hline Kp1 & 4.997 & -0.192 & 10 \\
\hline Ki1 & 2.694 & 0.055 & 10 \\
\hline Kd1 & 1.884 & -0.153 & 6.31 \\
\hline Kp2 & -0.974 & -0.077 & -0.62 \\
\hline Ki2 & -0.276 & -0.053 & -0.58 \\
\hline Kd2 & -0.591 & -0.234 & -1.7 \\
\hline Kp3 & 1.493 & -0.063 & 4.738 \\
\hline Ki3 & 2.144 & -0.178 & -5.948 \\
\hline Kd3 & -0.424 & -0.147 & -0.705 \\
\hline Kp4 & -0.161 & 0.15 & 0.355 \\
\hline Ki4 & -0.02 & 0.03 & 0.922 \\
\hline Kd4 & -0.837 & -0.214 & -1.36 \\
\hline
\end{tabular}

Table (4.3):PID tuned controller gains using ITAE ITSE

\begin{tabular}{|c|c|c|c|}
\hline PID & GA & PSO & ABC \\
\hline Kp1 & 4.85 & 0.051 & 7.93 \\
\hline Ki1 & 0.703 & 0.062 & 10 \\
\hline Kd1 & 1.29 & 0.037 & 2.678 \\
\hline Kp2 & 0.613 & -0.189 & -0.036 \\
\hline Ki2 & 1.78 & 0.029 & 1.1 \\
\hline Kd2 & -1.383 & -0.33 & -0.468 \\
\hline Kp3 & -1.094 & -0.332 & -0.066 \\
\hline Ki3 & 4.74 & -0.179 & 4.363 \\
\hline Kd3 & -0.619 & -0.273 & -0.743 \\
\hline Kp4 & -2.4 & -0.387 & -1.016 \\
\hline Ki4 & 0.354 & 0.077 & 0.553 \\
\hline Kd4 & 0.167 & -0.138 & -0.151 \\
\hline PID & GA & PSO & ABC \\
\hline
\end{tabular}

\begin{tabular}{|c|c|c|c|}
\hline Kp1 & 2.116 & 0.048 & 10 \\
\hline Ki1 & 0.62 & 0.037 & 1.228 \\
\hline Kd1 & 0.59 & 0.112 & 6.495 \\
\hline Kp2 & 0.187 & -0.047 & -1.205 \\
\hline Ki2 & 0.347 & 0.013 & 0.036 \\
\hline Kd2 & -0.426 & -0.829 & -0.078 \\
\hline Kp3 & $-\mathbf{0 . 6 1 8}$ & $-\mathbf{0 . 0 5 5}$ & 1.806 \\
\hline Ki3 & 3.34 & -0.081 & -5.322 \\
\hline Kd3 & -0.592 & -0.061 & -0.987 \\
\hline Kp4 & -0.696 & 0.095 & -0.508 \\
\hline Ki4 & 0.388 & 0.015 & 0.177 \\
\hline Kd4 & -0.193 & -1.086 & -0.695 \\
\hline
\end{tabular}

Table (4.4):PID tuned controller gains using ITSE

$\Delta \mathrm{F} 1$

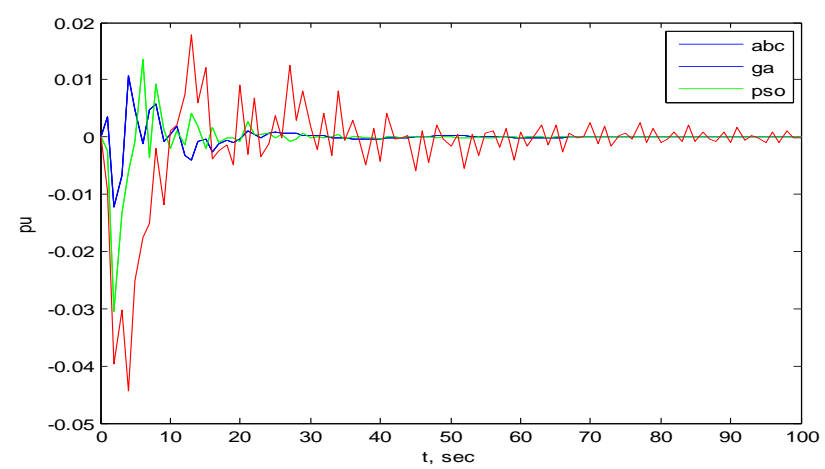

Figure (14): Time response of $\Delta F_{1}$ using IAE for Reheat Steam and Hydro Turbines following a step change of $1 \%$ in the load of area

Table(4.5): $\Delta \mathrm{F}_{1}$ settling time, raise time and maximum overshoot for Reheat Steam and Hydro Turbines for $1 \%$ load change in area1 using IAE

\begin{tabular}{|l|l|l|l|l|}
\hline & tr & ts & Max overshoot & time \\
\hline GA & 0.0029 & 27.517 & 0.0305 & 16.2148 \\
\hline PSO & 0.011 & 98.23 & 0.0444 & 9.206 \\
\hline ABC & 0.0042 & 40.91 & 0.0122 & 40.7947 \\
\hline
\end{tabular}

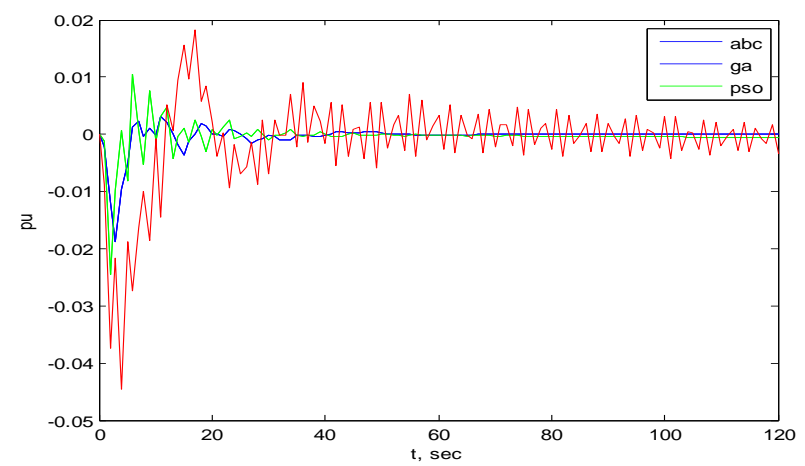

Figure (15): Time response of $\Delta \mathrm{F}_{1}$ using ISE for Reheat Steam and Hydro Turbines following a step change of $1 \%$ in the load of area 1 
Table (4.6): $\Delta \mathrm{F}_{1}$ settling time, raise time and maximum overshoot for Reheat Steam and Hydro Turbines for $1 \%$ load change in area1 using ISE

\begin{tabular}{|l|l|l|l|l|}
\hline & tr & ts & Max overshoot & time \\
\hline GA & 0.462 & 62.487 & 0.0245 & 14.3149 \\
\hline PSO & 0.3122 & 119.843 & 0.0445 & 7.441 \\
\hline ABC & 0.0041 & 48.7788 & 0.0187 & 45.7947 \\
\hline
\end{tabular}

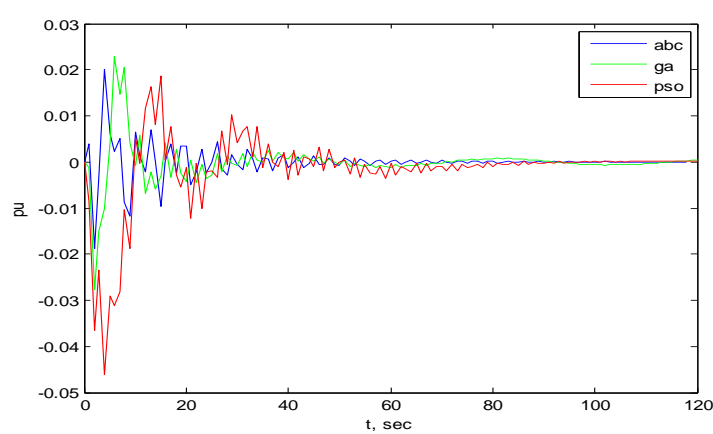

Figure (16): Time response of $\Delta F_{1}$ using ITAE for Reheat Steam and Hydro Turbines following a step change of $1 \%$ in the load of area 1

Table (4.7): $\Delta F_{1}$ settling time, raise time and maximum overshoot for Reheat Steam - Hydro Turbines for $1 \%$ load change in area1 using ITAE

\begin{tabular}{|l|l|l|l|l|}
\hline & tr & ts & Max overshoot & Time \\
\hline GA & 0.0208 & 112.4779 & 0.0277 & 28.6732 \\
\hline PSO & 0.0081 & 85.024 & 0.0462 & 11.9934 \\
\hline ABC & 0.0036 & 67.002 & 0.0201 & 40.6696 \\
\hline
\end{tabular}

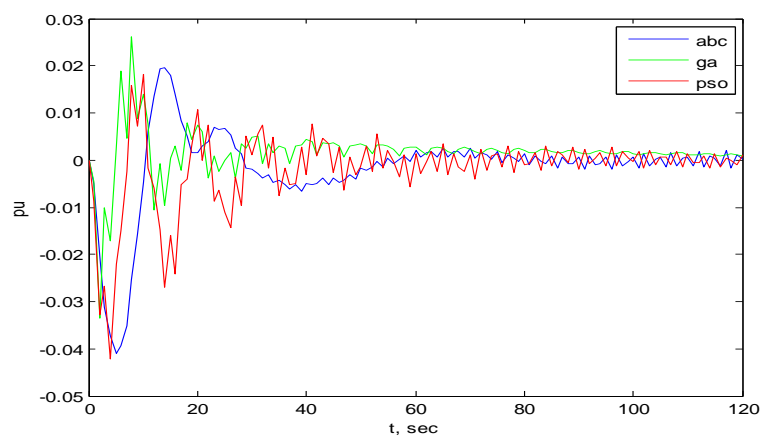

Figure (17): Time response of $\Delta F_{1}$ using ITSE for Reheat Steam and Hydro Turbines following a step change of $1 \%$ in the load of area 1
Table(4.13): $\Delta \mathrm{F}_{1}$ settling time, raise time and maximum overshoot for Reheat Steam and Hydro Turbines for $1 \%$ load change in area1 using ITS

$\Delta \mathbf{P}_{\text {tie,12 }}$

\begin{tabular}{|l|l|l|l|l|}
\hline & tr & ts & Max overshoot & Time \\
\hline GA & 0.0382 & 103.299 & 0.0335 & 20.3274 \\
\hline PSO & 0.049 & 119.604 & 0.0422 & 12.0407 \\
\hline ABC & 0.014 & 119.186 & 0.0409 & 39.5964 \\
\hline
\end{tabular}

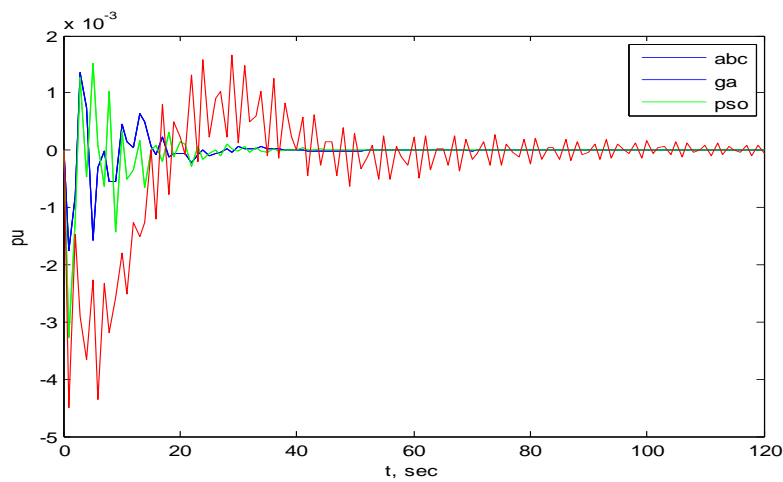

Figure (18): Time response of $\Delta \mathbf{P}_{\text {tie, } 12}$ using IAE for Reheat Steam and Hydro Turbines following a step change of $1 \%$ in the load of area 1

Table(4.9): $\Delta \mathbf{P}_{\text {tie, } 12}$ settling time, raise time and maximum overshoot for Reheat Steam and Hydro Turbines for 1\% load change in area1 using IAE

\begin{tabular}{|l|l|l|l|}
\hline & tr & ts & Max overshoot \\
\hline GA & $1.22 \mathrm{e}-04$ & 28.45 & 0.0033 \\
\hline PSO & 0.0115 & 119.416 & 0.0045 \\
\hline ABC & $2.29 \mathrm{e}-04$ & 34.9214 & 0.0018 \\
\hline
\end{tabular}

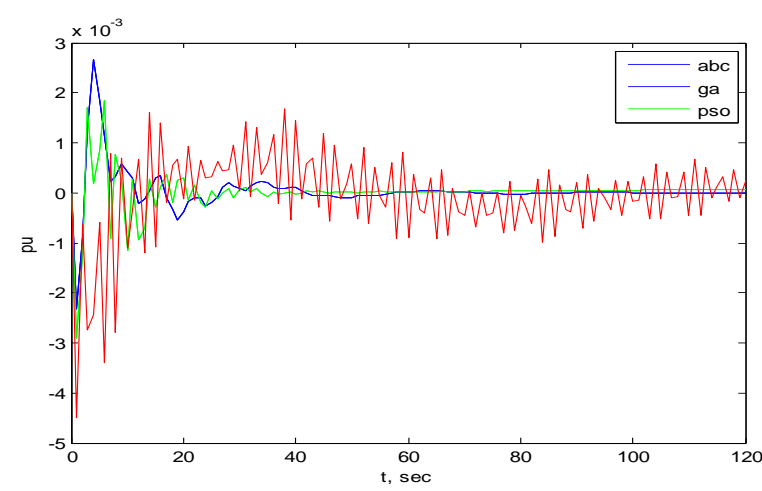

Figure (19):Time response of $\Delta \mathbf{P}_{\text {tie,12 }}$ using ISE for Reheat Steam and Hydro Turbines following a step change of $1 \%$ in the load of area 1 
Table (4.10): $\Delta P_{\text {tie,12}}$ settling time, raise time and maximum overshoot for Reheat Steam and Hydro Turbines for 1\% load change in area1 using ISE

\begin{tabular}{|l|l|l|l|}
\hline & tr & ts & Max overshoot \\
\hline GA & 0.0204 & 57.1188 & 0.0029 \\
\hline PSO & 0.0486 & 119.7366 & 0.0045 \\
\hline ABC & $7.23 \mathrm{e}-04$ & 51.8725 & 0.0027 \\
\hline
\end{tabular}

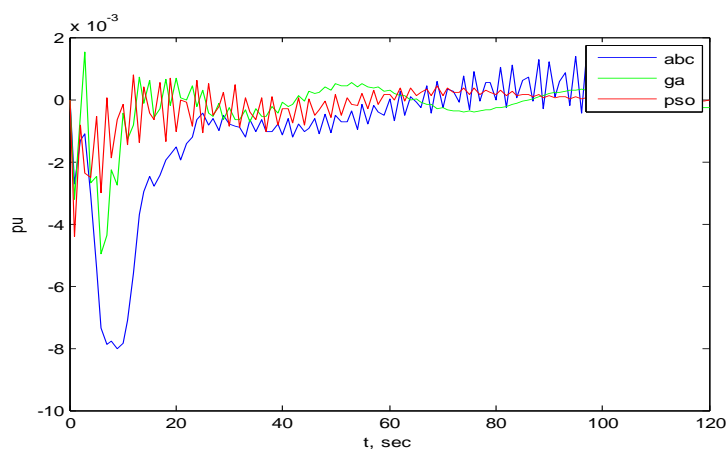

Figure (20): Time response of $\Delta \mathbf{P}_{\text {tie,12 }}$ using ITAE for Reheat Steam and Hydro Turbines following a step change of $1 \%$ in the load of area 1

Table (4.11): $\Delta \mathrm{P}_{\text {tie,12 }}$ settling time, raise time and maximum overshoot for reheat steam and Hydro turbines for $1 \%$ load change in area1 using ITAE

\begin{tabular}{|l|l|l|l|}
\hline & tr & ts & Max overshoot \\
\hline GA & 0.0639 & 112.396 & 0.005 \\
\hline PSO & 0.0063 & 95.37 & 0.0044 \\
\hline ABC & 14.1321 & 99.646 & 0.008 \\
\hline
\end{tabular}

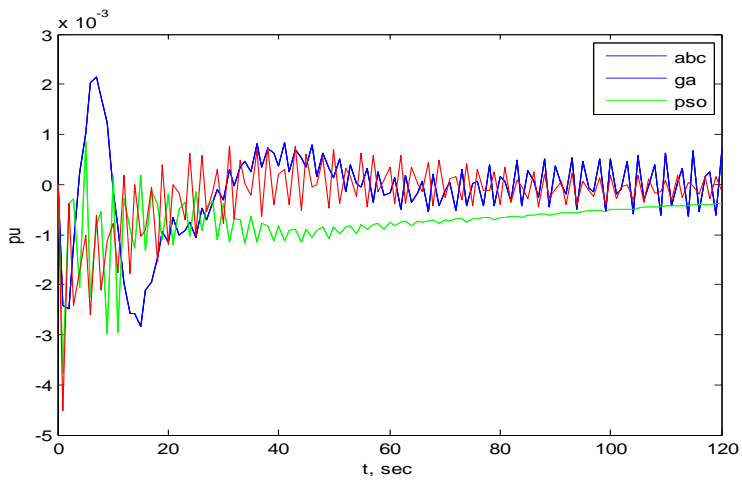

Figure (21):Time response of $\Delta \mathbf{P}_{\text {tie,12 }}$ using ITSE for Reheat Steam and Hydro Turbines following a step change of $1 \%$ in the load of area 1

Table (4.12): $\Delta \mathrm{P}_{\text {tie,12 }}$ settling time, raise time and maximum overshoot for reheat Steam and hydro turbines for $1 \%$ load change in area1 using ITSE

\begin{tabular}{|l|l|l|l|}
\hline & tr & ts & Max overshoot \\
\hline GA & 0.0789 & 109.69 & 0.0038 \\
\hline PSO & 0.0242 & 119.7 & 0.0045 \\
\hline ABC & 0.642 & 119.947 & 0.0028 \\
\hline
\end{tabular}

LFC Using Four Areas Power System With hybrid Units:
2. For $1 \%$ load change in area 1 : $1 \%$ IAE

Table (4.13):PID tuned controller gains using IAE ISE

\begin{tabular}{|c|c|c|c|}
\hline PID & GA & PSO & ABC \\
\hline Kp1 & 1.543 & 0.036 & 7.375 \\
\hline Ki1 & 1.416 & 0.406 & 10 \\
\hline Kd1 & 0.15 & 0.483 & 1.91 \\
\hline Kp2 & 0.159 & -0.04 & 2.093 \\
\hline Ki2 & 0.123 & 0.445 & 0.358 \\
\hline Kd2 & 0.049 & 0.2 & 6.977 \\
\hline Kp3 & -1.07 & 0.318 & 0.4 \\
\hline Ki3 & 2.07 & 0.498 & 0.61 \\
\hline Kd3 & -0.58 & -0.18 & -0.5 \\
\hline Kp4 & 0.792 & -0.09 & 4.868 \\
\hline Ki4 & 1.247 & 0.133 & 0.927 \\
\hline Kd4 & 0.457 & 0.324 & 4.481 \\
\hline
\end{tabular}

Table (4.14):PID tuned controller gains using ISE

ITAE

\begin{tabular}{|c|c|c|c|}
\hline PID & GA & PSO & ABC \\
\hline Kp1 & 1.567 & -0.708 & 7.28 \\
\hline Ki1 & 2.048 & 1.883 & 8.402 \\
\hline Kd1 & 0.896 & 0.48 & 1.856 \\
\hline Kp2 & 0.735 & 1.95 & -0.03 \\
\hline Ki2 & 0.066 & 0.649 & 7.314 \\
\hline Kd2 & 0.507 & 1.198 & 5.546 \\
\hline Kp3 & 0.24 & 1.028 & -0.31 \\
\hline Ki3 & 0.367 & 0.091 & 0.74 \\
\hline Kd3 & -0.6 & -0.28 & -2.88 \\
\hline Kp4 & -0.58 & 2.844 & 9.168 \\
\hline Ki4 & 0.767 & 0.165 & 1.912 \\
\hline Kd4 & 0.236 & 0.856 & 10 \\
\hline
\end{tabular}

Table (4.15):PID tuned controller gains using ITAE ITSE

\begin{tabular}{|c|c|c|c|}
\hline PID & GA & PSO & ABC \\
\hline Kp1 & 0.96 & 0.42 & 0.45 \\
\hline Ki1 & 1.48 & 0.91 & 0.39 \\
\hline Kd1 & 0.08 & -0.4 & -0.05 \\
\hline Kp2 & 0.15 & 0.27 & 0.49 \\
\hline Ki2 & 0.04 & 0.22 & 0.06 \\
\hline Kd2 & 0.11 & 1.59 & 0.02 \\
\hline Kp3 & -1.5 & -0.2 & -0.26 \\
\hline Ki3 & 0.72 & 0.53 & 0.16 \\
\hline Kd3 & -0.9 & -0.5 & -0.36 \\
\hline Kp4 & 0.66 & 0.98 & 0.04 \\
\hline Ki4 & 0.53 & -0.08 & -0.04 \\
\hline Kd4 & 0.58 & 1.22 & 0.48 \\
\hline
\end{tabular}


Table (4.16):PID tuned controller gains using ITSE

\section{$\Delta \mathbf{F 1}$}

\begin{tabular}{|c|c|c|c|}
\hline PID & GA & PSO & ABC \\
\hline Kp1 & -0.18 & -0.29 & 2.94 \\
\hline Ki1 & 0.206 & 1.264 & 2.237 \\
\hline Kd1 & -0.14 & -0.49 & 0.017 \\
\hline Kp2 & 0.124 & 1.044 & 0.109 \\
\hline Ki2 & 0.046 & 1.376 & 0.225 \\
\hline Kd2 & 1.452 & 0.621 & 0.149 \\
\hline Kp3 & -1.26 & 1.024 & -0.82 \\
\hline Ki3 & 0.036 & -0.03 & 1.222 \\
\hline Kd3 & -1.93 & -0.78 & -1.28 \\
\hline Kp4 & 0.425 & 0.029 & 7.53 \\
\hline Ki4 & 0.596 & -0.003 & 5.367 \\
\hline Kd4 & 1.208 & 0.357 & 1.508 \\
\hline
\end{tabular}

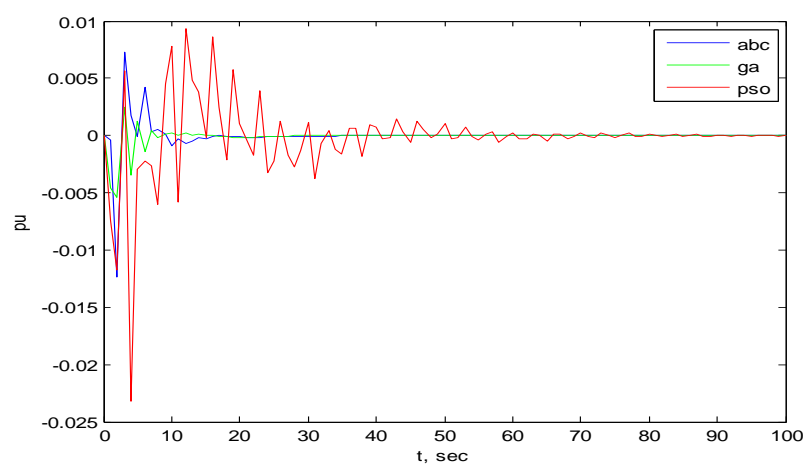

Figure (22): Time response of $\triangle F 1$ using IAE for hybrid system following a step change of $1 \%$ in the load of area 1

Table (4.17): $\Delta F 1$ settling time, raise time and maximum overshoot for hybrid system for $1 \%$ load change in area1 using IAE

\begin{tabular}{|l|l|l|l|l|}
\hline & tr & ts & Max overshoot & time \\
\hline GA & $5.9 \mathrm{e}-06$ & 23.4664 & 0.0054 & 18.76 \\
\hline PSO & 0.002 & 65.63 & 0.0232 & 4.47 \\
\hline ABC & $4.68 \mathrm{e}-04$ & 15.014 & 0.0124 & 45.45 \\
\hline
\end{tabular}

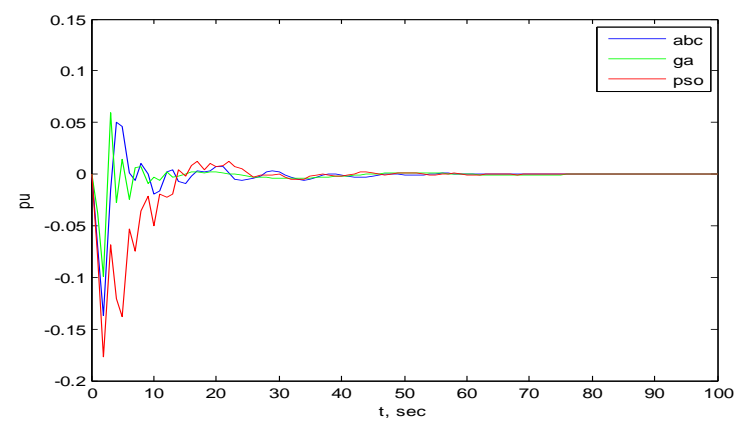

Figure (23): Time response of $\Delta$ F1using ISE for hybrid system following a step change of $1 \%$ in the load of area 1
Table (4.18): $\Delta F 1$ settling time, raise time and maximum overshoot for hybrid system for $1 \%$ load change in area1 using ISE

\begin{tabular}{|l|l|l|l|l|}
\hline & tr & ts & Max overshoot & time \\
\hline GA & $4.456 \mathrm{e}-05$ & 31.5108 & 0.0154 & 9.4041 \\
\hline PSO & 0.0014 & 63.0224 & 0.0182 & 3.4477 \\
\hline ABC & 0.0011 & 57.6934 & 0.0104 & 18.263 \\
\hline
\end{tabular}

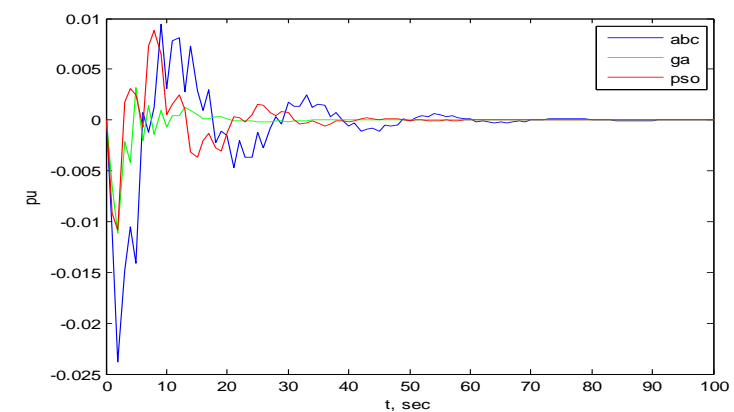

Figure (24): Time response of $\Delta$ F1using ITAE for Hybrid system following a step change of $1 \%$ in the load of area 1

Table(4.19): $\Delta$ F1settling time, raise time and maximum overshoot for hybrid system for $1 \%$ load change in area1 using ITAE

\begin{tabular}{|l|l|l|l|l|}
\hline & tr & ts & Max overshoot & Time \\
\hline GA & $1.6 \mathrm{e}-04$ & 19.368 & 0.0112 & 17.633 \\
\hline PSO & $5.12 \mathrm{e}-05$ & 43.08 & 0.0109 & 14.2717 \\
\hline ABC & 0.0022 & 54.73 & 0.0238 & 45.5 \\
\hline
\end{tabular}

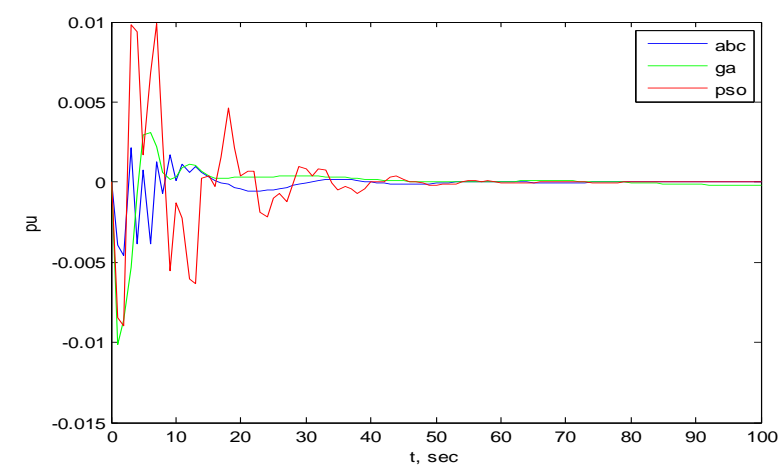

Figure (25): Time response of $\Delta$ F1using ITSE for Hybrid system following a step change of $1 \%$ in the load of area 1

Table (4.20): $\Delta F 1$ settling time, raise time and maximum overshoot for hybrid system for $1 \%$ load change in area1 using ITSE

\begin{tabular}{|l|l|l|l|l|}
\hline & tr & ts & Max overshoot & Time \\
\hline GA & 0.016 & 78.39 & 0.0101 & 18.0297 \\
\hline PSO & $6.05 \mathrm{e}-04$ & 50.088 & 0.0099 & 15.0919 \\
\hline ABC & $7.6 \mathrm{e}-05$ & 49.355 & 0.0046 & 50.7947 \\
\hline \multicolumn{4}{|l}{$\Delta \mathrm{P}_{\text {tie, } 12}$}
\end{tabular}




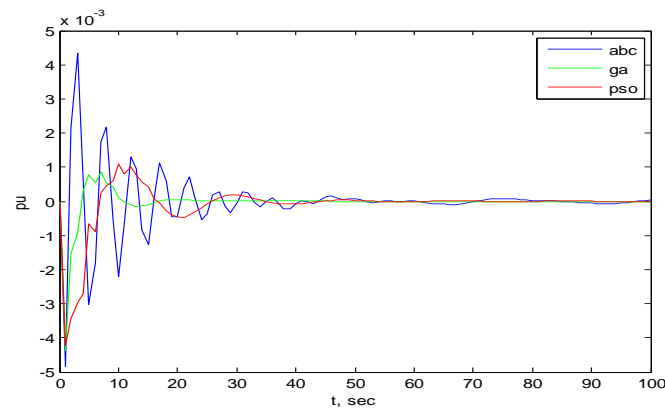

Figure (26): Time response of $\Delta P_{\text {tie,12 }}$ using IAE for Hybrid system following a step change of $1 \%$ in the load of area 1

Table (4.21): $\Delta \mathrm{P}_{\text {tie,12 }}$ settling time, raise time and maximum overshoot for hybrid system for $1 \%$ load change in area1 using IAE

\begin{tabular}{|l|l|l|l|}
\hline & tr & ts & Max overshoot \\
\hline GA & 0.003 & 14.7879 & 0.0044 \\
\hline PSO & $2.03 \mathrm{e}-05$ & 32.98 & 0.0052 \\
\hline ABC & 0.0054 & 45.34 & 0.0043 \\
\hline
\end{tabular}

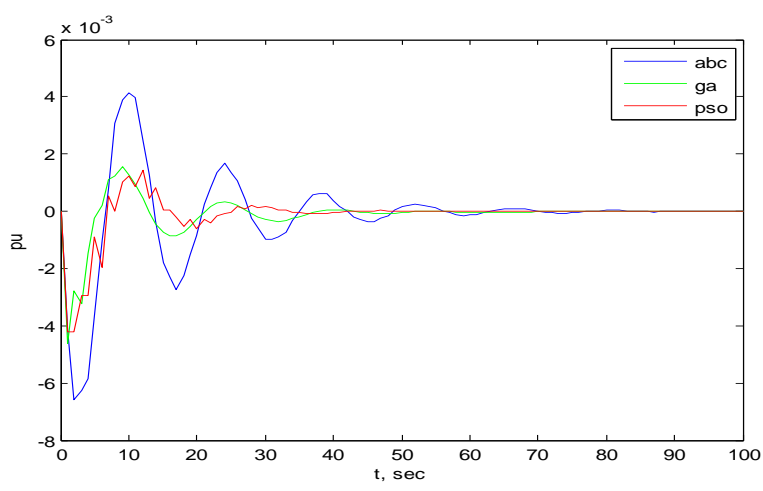

Figure (27): Time response of $\Delta \mathrm{P}_{\text {tie,12 }}$ using ISE for Hybrid system following a step change of $1 \%$ in the load of area 1

Table (4.22): $\Delta P_{\text {tie, } 12}$ settling time, raise time and maximum overshoot for hybrid system for $1 \%$ load change in area1 using ISE

\begin{tabular}{|l|l|l|l|}
\hline & tr & ts & Max overshoot \\
\hline GA & 0.0013 & 36.064 & 0.0046 \\
\hline PSO & $2.09 \mathrm{e}-05$ & 31.404 & 0.0042 \\
\hline ABC & 0.001 & 60 & 0.0066 \\
\hline
\end{tabular}

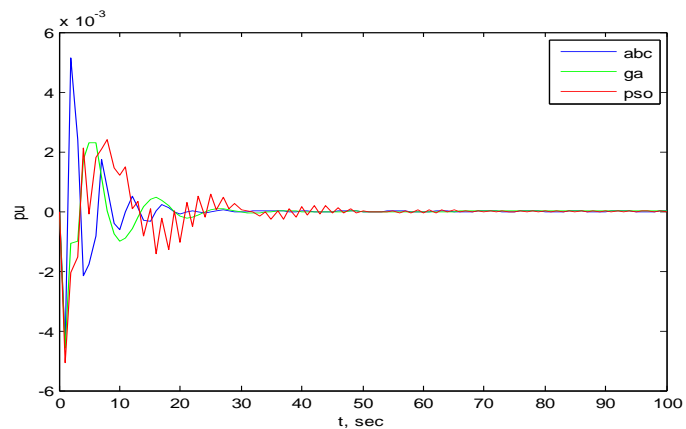

Figure (28): Time response of $\Delta \mathrm{P}_{\text {tie,12 }}$ using ITAE for Hybrid system following a step change of $1 \%$ in the load of area 1

Table (4.23): $\Delta P_{\text {tie,12 }}$ settling time, raise time and maximum overshoot for hybrid system for $1 \%$ load change in area1 using ITAE

\begin{tabular}{|l|l|l|l|}
\hline & tr & ts & Max overshoot \\
\hline GA & $5.36 \mathrm{e}-05$ & 27.23 & 0.0046 \\
\hline PSO & $3.21 \mathrm{e}-04$ & 46.213 & 0.0051 \\
\hline ABC & $8.8 \mathrm{e}-06$ & 18.2133 & 0.0051 \\
\hline
\end{tabular}

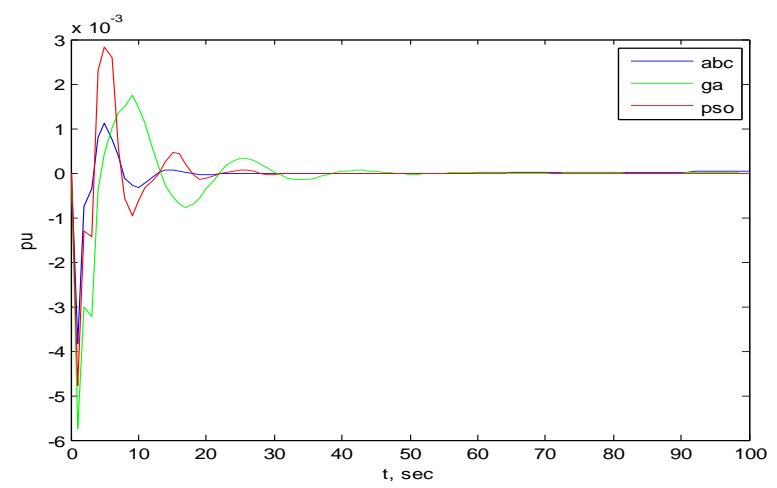

Figure (29): Time response of $\Delta \mathrm{P}_{\text {tie,12 }}$ using ITSE for Hybrid system following a step change of $1 \%$ in the load of area 1

Table (4.24): $\Delta \mathrm{P}_{\text {tie,12 }}$ settling time, raise time and maximum overshoot for hybrid system for $1 \%$ load change in area1 using ITSE

\begin{tabular}{|l|l|l|l|}
\hline & tr & ts & Max overshoot \\
\hline GA & $1.66 \mathrm{e}-04$ & 40.917 & 0.005 \\
\hline PSO & $8.6 \mathrm{e}-05$ & 50.43 & 0.0053 \\
\hline ABC & $1.814 \mathrm{e}-04$ & 52.309 & 0.0043 \\
\hline
\end{tabular}

\section{CONCLUSION}

A load frequency control algorithm is presented in this paper to correct the frequency deviation and tie line power deviation following a step load change. The parameters tuning of PID controllers based on Artificial intelligence techniques is studied. AI techniques like Particle Swarm Optimization (PSO) algorithm and Genetic Algorithm (GA) And Artificial Bee Colony (ABC)are presented.

The AI techniques are applied to control the frequency of two four areas power systems. The first system is a non-hybrid which consists of steam and hydro units only. The second power system is a hybrid which consists of steam, hydro, 
gas, and diesel units. It was found from a control point of view that in a hybrid system the load frequency controller can chase the load fluctuation in a short time.

In this paper, each $\mathrm{AI}$ technique gives the optimum values of the PID parameters based on four objective functions (performance indices). These are the Integral of Absolute Error (IAE), Integral of Squared Error( ISE), Integral of Time multiply by Absolute Error (ITAE), and Integral of Time multiplied by squared error( ITSE). It was found that the optimization technique based on performance index Integral of Absolute Error (IAE) give an optimum dynamic performance.

From the results, It can be observed that the hybrid system gives best results in the term of settling time and maximum overshoot.

It was also observed that in most of the cases the PID parameters tuned by $\mathrm{ABC}$ technique give the best performance in term of settling time and the best performance in term of overshoot. The results obtained reveal that the PID parameters tuned by PSO technique give a Poor performance for both settling time and maximum overshoot.

\section{ACKNOWLEDGMENTS}

The authors are thankful to the Electrical Engineering Department, Faculty of Engineering, Al-Mustansiriyah University, Baghdad, Iraq for providing the facilities .

\section{REFERENCES}

[1] K.S.S. Ramakrishna, ' Load frequency control of interconnected hydro-thermal power systems',International Conference on Energy and Environment 2006 (ICEE 2006), New Delhi, India.

[2] Vikas Jain, ' Modeling and simulation of Load Frequency Control in Automatic Generation Control using Genetic Algorithms GA Technique', IJISET-International Journal of Innovative Science, Engineering \& Technology, Vol. 1 Issue 8,October 2014

[3] A. Soundarrajan, 'Effect of Non-linearity's in Fuzzy Based Load Frequency Control', International Journal of Electronic Engineering Research,Volume 1 Number 1 (2009) pp. 37-51.

[4] Ahmed M. Kassem,' Neural predictive controller of a two-area load frequency control for interconnected power system', Ain Shams Engineering Journal (2010) 1, 49-58, Egypt, 2010.

[5] Surya Prakash, 'Artificial Intelligent \&PI in Load Frequency Control of Interconnected (thermal-hydro) Power System', International Journal of Computer
Science \& Emerging Technologies (E-ISSN: 2044-6004) Volume 1, Issue 4, December 2010 India.

[6] Haluk Gozde ,' Comparative performance analysis of Artificial Bee Colony algorithm in automatic generation control for interconnected reheat thermal power system' , Electrical Power and Energy Systems 42 (2012) 167178, Ankara, Turkey.

[7] Mohammad Soroush Soheilirad, ' Tuning of PID Controller for Multi Area Load Frequency Control by Using Imperialist Competitive Algorithm ICA', Journal of Basic and Applied Scientific Research, Journal of Basic and Applied Scientific Research,Malaysia,2012.

[8] R. Arivoli , ' CPSO based LFC for a Two-area Power System with GDB and GRC Nonlinearities Interconnected through TCPS in Series with the TieLine', International Journal of Computer Applications (0975 - 8887) Volume 38- No.7, January 2012.

[9] Mohammad Amin Hedari, ' Fuzzy based load frequency controller for multi area power system', Technical Journal of Engineering and Applied Sciences, Iran, 2013.

[10] infocen@moelc.gov.iq

[11] Dervis KARABOGA,' An idea based on Honey Bee Swarm for Numerical Optimization', TECHNICAL REPORT-TR06, OCTOBER, 2005, Kayseri/Turkey, 2005.

[12] www.elnadabee.com.

\section{APPENDIX A1}

The nominal parameters of the non-Hybrid Power System are: $\mathrm{F}=50 \mathrm{~Hz}, \mathrm{R}=2.4 \mathrm{~Hz} /$ p.u.MW , $\mathrm{b}=0.425$ p.u.MW/Hz, $\mathrm{K}_{\mathrm{p}}=$ $120 \mathrm{~Hz} /$ p.u.MW $, \mathrm{T}_{\mathrm{p}}=20 \mathrm{Sec}, \mathrm{T}_{\mathrm{g}}=0.08 \mathrm{Sec}, \mathrm{T}_{\mathrm{t}}=0.3 \mathrm{Sec}$, $\mathrm{K}_{\mathrm{r}}=0.5 \mathrm{Sec}, \mathrm{T}_{\mathrm{r}}=10 \mathrm{Sec}, \mathrm{T}_{\mathrm{gh}}=0.2 \mathrm{Sec}, \mathrm{T}_{\mathrm{W}}=1 \mathrm{Sec}, \mathrm{T} 1=$ $5 \mathrm{Sec}, \mathrm{T} 2=28.75 \mathrm{Sec}, \mathrm{T}_{12}=\mathrm{T}_{13}=\mathrm{T}_{14}=\mathrm{T}_{23}=\mathrm{T}_{24}=\mathrm{T}_{34}=$ $0.0866 \mathrm{Sec}$.

\section{APPENDIX A2}

The nominal parameters of the Hybrid Power System are:

$\mathrm{F}=50 \mathrm{~Hz}, \mathrm{R}=2.4 \mathrm{~Hz} /$ p.u.MW , $\mathrm{b}=0.425$ p.u.MW/Hz, $\mathrm{K}_{\mathrm{p}}=$ $120 \mathrm{~Hz} /$ p.u.MW $, \mathrm{T}_{\mathrm{p}}=20 \mathrm{Sec}, \mathrm{T}_{\mathrm{g}}=0.08 \mathrm{Sec}, \mathrm{T}_{\mathrm{t}}=0.3 \mathrm{Sec}$, $\mathrm{K}_{\mathrm{r}}=0.5 \mathrm{Sec}, \mathrm{T}_{\mathrm{r}}=10 \mathrm{Sec}, \mathrm{T}_{\mathrm{gh}}=0.2 \mathrm{Sec}, \mathrm{T}_{\mathrm{W}}=1 \mathrm{Sec}, \mathrm{T} 1=$ $5 \mathrm{Sec}, \mathrm{T} 2=28.75 \mathrm{Sec}, \mathrm{K}_{\text {diesel }}=16.5, \mathrm{Z}=0.6 \mathrm{Sec}, \mathrm{Y}=1$ Sec, $\mathrm{a}=1, \mathrm{~b} 1=0.05, \mathrm{c}=1, \mathrm{~T}_{\mathrm{f}}=0.23 \mathrm{Sec}, \mathrm{T}_{\mathrm{CR}}=0.3 \mathrm{Sec}$, $\mathrm{T}_{\mathrm{CD}}=0.2 \mathrm{Sec}, \mathrm{T}_{12}=\mathrm{T}_{13}=\mathrm{T}_{14}=\mathrm{T}_{23}=\mathrm{T}_{24}=\mathrm{T}_{34}=0.0866$ $\mathrm{Sec}$. 